\title{
Calcium-permeable ion channels in control of autophagy and cancer
}

\section{Artem Kondratskyi ${ }^{\dagger}$, Maya Yassine ${ }^{\dagger}$, Kateryna Kondratska, Roman Skryma, Christian Slomianny and Natalia Prevarskaya*}

Laboratory of Excellence, Equipe Labellisée par la Ligue Nationale Contre le Cancer, Ion Channels Science and Therapeutics, INSERM, U-1003, Université Lille 1 ، Villeneuve d'Ascq, France

\section{Edited by:}

Annarosa Arcangeli, University of

Florence, Italy

Reviewed by:

Alberto Passi, Università

dell'Insubria, Italy

Ildikò Szabò, University of Padova, Italy

*Correspondence:

Natalia Prevarskaya, Laboratory of Cell Physiology, INSERM U 1003,

Bat. SN 3, UFR de Biologie,

Université Lille 1, 59655

Villeneuve d'Asq, France

e-mail: natacha.prevarskaya@

univ-lille $1 . f r$

${ }^{\dagger}$ These authors have contributed equally to this work.
Autophagy, or cellular self-eating, is a tightly regulated cellular pathway the main purpose of which is lysosomal degradation and subsequent recycling of cytoplasmic material to maintain normal cellular homeostasis. Defects in autophagy are linked to a variety of pathological states, including cancer. Cancer is the disease associated with abnormal tissue growth following an alteration in such fundamental cellular processes as apoptosis, proliferation, differentiation, migration and autophagy. The role of autophagy in cancer is complex, as it can promote both tumor prevention and survival/treatment resistance. It's now clear that modulation of autophagy has a great potential in cancer diagnosis and treatment. Recent findings identified intracellular calcium as an important regulator of both basal and induced autophagy. Calcium is a ubiquitous secondary messenger which regulates plethora of physiological and pathological processes such as aging, neurodegeneration and cancer. The role of calcium and calcium-permeable channels in cancer is well-established, whereas the information about molecular nature of channels regulating autophagy and the mechanisms of this regulation is still limited. Here we review existing mechanisms of autophagy regulation by calcium and calcium-permeable ion channels. Furthermore, we will also discuss some calcium-permeable channels as the potential new candidates for autophagy regulation. Finally we will propose the possible link between calcium permeable channels, autophagy and cancer progression and therapeutic response.

\section{Keywords: calcium, autophagy, TRP, ion channels, cancer}

\section{AUTOPHAGY}

Autophagy is a cellular catabolic process for the degradation and recycling of protein aggregates, long-lived proteins and damaged organelles to maintain cellular homeostasis (Ravikumar et al., 2010; Chen and Klionsky, 2011). Normally, autophagy occurs under basal conditions but it can be stimulated in response to different types of cellular stress, such as nutrient starvation, hypoxia, endoplasmic reticulum (ER) stress, oxidative stress, mitochondrial damage as well as treatment with some pharmacological agents (Kroemer et al., 2010). To date, three types of autophagy have been described, including macroautophagy, microautophagy, and chaperone-mediated autophagy (CMA) (Klionsky, 2005). These types differ in their functions and regulatory mechanisms. During macroautophagy, further mentioned as autophagy, cytoplasmic components are engulfed by double membrane structures termed autophagosomes that mature by fusing first with late endosomes or directly with lysosomes to form autolysosomes. Finally, the content of autolysosome together with its inner membrane is degraded by lysosomal hydrolases to be reused in the cell (Ravikumar et al., 2010; Chen and Klionsky, 2011).

The process of autophagosome formation consists of several stages, namely initiation, elongation and maturation and fusion. At present, around 30 autophagy-related genes are identified, and most of them have mammalian orthologs (Ravikumar et al., 2010). These genes are implicated in different stages of autophagy. Thus, the autophagosome formation requires the activity of the class III phosphatidylinositol 3-kinase (PI3K), Vps34. Mammalian Atg18 homolog WIPI-1 binds to PI3P, the product of Vps34 activity, and is recruited to autophagosomal membrane. Vps34 is a part of a protein complex containing Beclin1/Atg6, p150/Vps15 and Atg14/barkor proteins (He and Levine, 2010). Another complex implicated in the initiation stage of autophagosome formation is the focal adhesion kinase family interacting protein FIP200-ULK1/2/Atg1-Atg13 complex, where Atg13, ULK1, and ULK2 proteins have been shown to be direct targets of the mammalian target of rapamycin (mTOR) (Mizushima, 2010). Under nutrient-rich conditions, mTOR is associated with this complex, whereas under starvation conditions inhibition of mTOR causes its dissociation from the complex and leads to activation of ULK1/2, subsequent phosphorylation of FIP200 and autophagy induction (Mizushima, 2010; Kim et al., 2011). The elongation stage requires cleavage of the microtubule-associated protein 1 light chain 3 (Atg8/LC3) by Atg4, resulting in the formation of cytosolic LC3-I protein, which is conjugated to phosphatidylethanolamine (PE) to form membrane bound LC3-II (Tanida et al., 2004). Another stage is the formation of Atg5-Atg12-Atg16L1 protein complex which 
facilitates LC3-I conjugation to PE and determines the sites of LC3 lipidation. Thus, LC3-II is specifically targeted to the autophagosome membrane and remains associated with autophagosome even after fusion with the lysosomes (Geng and Klionsky, 2008; Ravikumar et al., 2010). This peculiarity makes it a useful marker for autophagy research (Klionsky et al., 2012).

\section{AUTOPHAGY IN CANCER}

Autophagy is thought to be predominantly a cell-survival mechanism. Under basal conditions, autophagy helps to maintain cellular homeostasis through the elimination of damaged organelles and protein aggregates, whereas in stress autophagy provides nutrients from macromolecules, produces energy, removes potentially dangerous elements thus assures cytoprotective response to support cell survival (Mizushima et al., 2008; Ravikumar et al., 2010). Deregulation of autophagy is known to affect many physiological processes and has been implicated in a number of diseases, such as neurodegenerative disorders and cancer (Choi et al., 2013). In cancer, current evidence indicate that autophagy may act as a tumor suppressor, in particular at the early stages of tumor initiation (White, 2012). Indeed, a number of autophagy related proteins, including Beclin1 (Liang et al., 1999; Yue et al., 2003), ATG5 (Yousefi et al., 2006; Takamura et al., 2011), ATG4c (Marino et al., 2007), and ATG7 (Takamura et al., 2011) as well as some accessory proteins (Bif1, UVRAG) (Liang et al., 2007a; Takahashi et al., 2007) have been shown to be tumor suppressors. In addition, several oncosuppressor proteins, such as DAPK (Inbal et al., 2002), PTEN (Arico et al., 2001), TSC1/2, p53 (Feng et al., 2005) and LKB1 (Liang et al., 2007b) have been recently shown to stimulate autophagic process, while a number of oncoproteins, like Bcl-2 (Pattingre et al., 2005), AKT and class I PI3K (Arico et al., 2001) negatively regulate autophagy (Rubinsztein et al., 2012). One of the possible mechanisms for antitumorigenic functions of autophagy is based on its cytoprotective role. More specifically, inhibition of autophagy will favor DNA damage, genomic instability and thus tumorigenesis through the accumulation of protein aggregates, damaged mitochondria and reactive oxygen species (ROS) (White, 2012).

In contrast, in established tumors, autophagy being a primarily survival mechanism can support cancer cell survival in harsh conditions, characterized by nutrient deficiency and hypoxia (Degenhardt et al., 2006; White, 2012). Indeed, accumulated data suggest that autophagy inhibition by genetic or chemical means facilitates apoptotic cell death and inhibits tumor cells growth in several cancers (Amaravadi et al., 2007; Takamura et al., 2011; Yang et al., 2011a,b). In addition, elevated autophagy is often detected in cancer cells in response to radiation and chemotherapy (Ito et al., 2005; Kondo et al., 2005; White, 2012). Furthermore, autophagy seems to contribute to the therapeutic resistance of some cancers, as inhibition of autophagy has been shown to sensitize tumor cells to chemotherapy treatments (Guo et al., 2012; Selvakumaran et al., 2013). Therefore, autophagy inhibition as an adjuvant to chemotherapy represents a promising strategy in the treatment of some cancers (Amaravadi et al., 2011; White, 2012). Indeed, more than 20 clinical trials are currently evaluating the efficacy of chloroquine and hydroxychloroquine (autophagy inhibitors) in treatment of different cancers either in monotherapy or in combination with other anticancer agents. The preliminary results of many of these trials show apparent antitumour activity (Yang et al., 2011b; Kimura et al., 2013). In addition to chloroquine and hydroxychloroquine another autophagy inhibitors, including 3-Methyladenine, bafilomycin A1 and pepstatin A have been shown to enhance the antitumour efficacy of chemotherapeutic drugs both in vitro and in vivo (Hsu et al., 2009; Li et al., 2010; Cheong et al., 2012; Lamoureux and Zoubeidi, 2013). However, it should be noted that all these autophagy inhibitors are not specific and can modulate other cellular processes, such as endocytosis, lysosomal function etc. Hence unexpected side effects could occur when treating patients with these drugs. Therefore, more specific and potent autophagy inhibitors are clearly needed.

Thus, figuring out whether to stimulate or inhibit autophagy in each particular case will provide a powerful approach to treat cancer.

\section{CALCIUM, $\mathrm{Ca}^{2+}$-PERMEABLE ION CHANNELS AND CANCER}

Changes in the cytosolic free $\mathrm{Ca}^{2+}$ concentration play a central role in many fundamental cellular processes including muscle contraction, transmitter release, cell proliferation, differentiation, gene transcription and cell death (Berridge et al., 2000). Giving that $\mathrm{Ca}^{2+}$ controls so many vital processes, disturbance of the $\mathrm{Ca}^{2+}$ homeostasis regulatory mechanisms leads to a vast variety of severe pathologies, including cancer. Indeed, the role of $\mathrm{Ca}^{2+}$ is well-established in many cell signaling pathways involved in carcinogenesis (Monteith et al., 2007, 2012; Prevarskaya et al., 2011).

Increase in cytosolic calcium can occur as a result of $\mathrm{Ca}^{2+}$ influx from the extracellular space and $\mathrm{Ca}^{2+}$ release from intracellular sources. Both $\mathrm{Ca}^{2+}$ influx and $\mathrm{Ca}^{2+}$ release are tightly controlled by numerous regulatory systems that provide the specific spatial and temporal characteristics of an intracellular calcium signal that are required for sustaining certain cellular functions (Berridge et al., 2000).

Mitochondrial, ER, lysosomal and cytosolic calcium levels are regulated by calcium permeable ion channels localized either on the membranes of the intracellular organelles or on the plasma membrane (Berridge et al., 2003; Rizzuto et al., 2012). The calcium permeable channels, including families of transient receptor potential (TRP) channels, store-operated channels (SOCs), voltage-gated calcium channels, two-pore channels, mitochondrial permeability transition pore (MPTP), mitochondrial calcium uniporter (MCU), IP3 and ryanodine receptors and others contribute to changes in $\left[\mathrm{Ca}^{2+}\right]_{\mathrm{i}}$ by providing $\mathrm{Ca}^{2+}$ entry pathways, by modulating the driving force for the $\mathrm{Ca}^{2+}$ entry, and also by providing intracellular pathways for $\mathrm{Ca}^{2+}$ uptake/release into/from cellular organelles (Berridge et al., 2003; Pedersen et al., 2005; Bernardi and von Stockum, 2012; Rizzuto et al., 2012).

Thus, modulation of calcium permeable ion channel's expression/function affects intracellular $\mathrm{Ca}^{2+}$ concentrations and consequently calcium dependent processes, such as proliferation, apoptosis and autophagy (Flourakis and Prevarskaya, 2009; Decuypere et al., 2011a; Dubois et al., 2013). Indeed, defects in $\mathrm{Ca}^{2+}$ channels expression/function are involved in a number of pathologies, including tumorigenesis, since increased expression 
of $\mathrm{Ca}^{2+}$ channels could lead to elevated cytosolic $\mathrm{Ca}^{2+}$ levels and promotion of $\mathrm{Ca}^{2+}$-dependent proliferative pathways (Nilius, 2007; Prevarskaya et al., 2010). As an example, several members of the TRP family of ion channels, namely TRPC1, TRPC3, TRPC6, TRPV1, TRPV6, TRPM1, TRPM4, TRPM5, TRPM7, and TRPM8, show altered expression in cancer cells (Shapovalov et al., 2011). The involvement of SOCs, MPTP, MCU, IP3 receptors and ryanodine receptors in the regulation of cell death has also been described (Hajnoczky et al., 2000; Boehning et al., 2004; Flourakis et al., 2010; Wong et al., 2012b; Bernardi, 2013; Curry et al., 2013; Dubois et al., 2013; Qiu et al., 2013).

\section{ROLE OF Ca ${ }^{2+}$ IN AUTOPHAGY}

Recent findings identified intracellular calcium as a key regulator of both basal (Cardenas et al., 2010) and induced (HoyerHansen et al., 2007) autophagy. The complex role for $\mathrm{Ca}^{2+}$ in autophagy regulation has become obvious since 1993, when the first report linking autophagy and intracellularly sequestered calcium was published (Gordon et al., 1993). Indeed, Gordon et al. demonstrated that decrease as well as increase in cytosolic $\mathrm{Ca}^{2+}$ levels inhibited autophagy in rat hepatocytes (Gordon et al., 1993). And till now, the data on the mechanisms by which calcium controls autophagy remain rather controversial. Several groups reported inhibitory actions of calcium on autophagy, while another proposed mechanisms for calcium to activate autophagy (Decuypere et al., 2011a; Cardenas and Foskett, 2012; Parys et al., 2012). Indeed, Hoyer-Hansen and colleagues provided evidence that a rise in the free cytosolic calcium is a potent inducer of macroautophagy (Hoyer-Hansen et al., 2007). They demonstrated that $\mathrm{Ca}^{2+}$ mobilizing agents, namely vitamin D3, thapsigargin, ATP and ionomycin, stimulate autophagy via a signaling pathway involving $\mathrm{Ca}^{2+}$-activated kinase CAMKKbeta, which directly activates AMPK to inhibit mTOR (HoyerHansen et al., 2007). Recently, this pathway was shown to be required for amyloid-beta peptide induced autophagosome formation (Son et al., 2012). $\mathrm{Ca}^{2+} / \mathrm{CAMKK-beta/AMPK}$ pathway, although mTOR-independent, has been found to be involved in the leucine-rich repeat kinase-2 (LRRK2) induced autophagy (Gomez-Suaga et al., 2012). Authors proposed the mechanism in which LRRK2 activates NAADP receptors, in particular TPC2, leading to $\mathrm{Ca}^{2+}$ mobilization from acidic stores that in turn stimulates $\mathrm{Ca}^{2+}$-induced $\mathrm{Ca}^{2+}$ release from ER and subsequent CAMKK-beta/AMPK pathway activation (Gomez-Suaga et al., 2012). In all the cases discussed above, buffering of cytosolic $\mathrm{Ca}^{2+}$ with BAPTA-AM effectively inhibited autophagosomes accumulation, confirming the role of $\mathrm{Ca}^{2+}$. Another evidence supporting stimulatory effect of $\mathrm{Ca}^{2+}$ on autophagy is that exogenously introduced calcium in the form of calcium phosphate precipitates induces macroautophagy, which is Beclin1, Atg5 and PI3K class III dependent (Gao et al., 2008). This effect could be antagonized by extra- or intra-cellular calcium chelation.

In line with activatory role of calcium in autophagy, Sakaki et al. showed that $\mathrm{Ca}^{2+}$-dependent activation of protein kinase Ctheta is required for ER-stress induced autophagy but not for starvation induced autophagy (Sakaki et al., 2008).

In another studies calcium/calmodulin dependent death associated protein kinase (DAPK) was shown to positively regulate autophagy in a Beclin1 dependent manner. Thus, DAPK phosphorylates Beclin1, thereby promoting its dissociation from Bcl$\mathrm{X}_{\mathrm{L}}$ and Bcl-2 inhibitory proteins (Zalckvar et al., 2009a,b).

On the contrary, Khan et al suggested that basal autophagic flux may be negatively regulated by IP3R-dependent $\mathrm{Ca}^{2+}$ release from the ER (Khan and Joseph, 2010). The authors proposed a mechanism in which cytosolic $\mathrm{Ca}^{2+}$ elevation acts to maintain an elevated mTORC1 activity through AMPK independent pathway (Khan and Joseph, 2010). Furthermore, amino acids were shown to induce an increase in $\left[\mathrm{Ca}^{2+}\right]_{i}$, supposedly through the influx of extracellular $\mathrm{Ca}^{2+}$, which acts to enhance the binding of $\mathrm{Ca}^{2+} / \mathrm{CaM}$ to $\mathrm{hVps} 34$, resulting in mTOR activation (Gulati et al., 2008). This pathway could also lead to autophagy inhibition.

Thus, calcium is likely to have different regulatory effects on autophagy, depending on spatial and temporal parameters of $\mathrm{Ca}^{2+}$ signaling, nutrient and growth factor availability, as well as pathology (cancer, neurodegenerative disorders, inflammation etc.) (Decuypere et al., 2011a).

\section{CALCIUM PERMEABLE CHANNELS IN THE CONTROL OF AUTOPHAGY}

Modulation of calcium permeable channels expression/function affects intracellular $\mathrm{Ca}^{2+}$ concentrations and, consequently calcium dependent processes, such as proliferation, apoptosis and autophagy. The role of calcium-permeable channels for proliferation and apoptosis is largely recognized (Monteith et al., 2007; Flourakis and Prevarskaya, 2009; Prevarskaya et al., 2010; Dubois et al., 2013), whereas the information about molecular nature of channels regulating autophagy and the mechanisms of this regulation is still limited.

Hereafter, we will provide an overview of the literature on this subject and discuss the possible involvement of calcium permeable ion channels in the regulation of autophagy.

Most reports considering calcium permeable channels as autophagy regulators focused on the inositol trisphosphate receptor (IP3R), the main intracellular $\mathrm{Ca}^{2+}$ release channel (Parys et al., 2012). Together these reports suggested a complex role for IP3R, since both stimulatory as well as inhibitory functions for IP3R toward autophagy have been described.

Thus, in one paper it was suggested that cadmium $\left(\mathrm{Cd}^{2+}\right)$ induces autophagy through elevation of cytosolic calcium via IP3R and subsequent extracellular signal-regulated kinase (ERK) activation (Wang et al., 2008). As a proof for this, the authors showed that 2-aminoethoxydiphenil borate (2-APB), a blocker of IP3R, suppressed, while knockdown of calcineurin, a putative IP3R inhibitor, increased $\mathrm{Cd}^{2+}$-induced autophagy (Wang et al., 2008). However, 2-APB was shown to modulate a number of TRP channels, SERCA pump and SOCs (Peppiatt et al., 2003; Clapham, 2007) and as to calcineurin, its role in the IP3R regulation is debated at present (Bultynck et al., 2003).

In another study, IP3R was shown to be required for differentiation factor DIF-induced autophagic cell death in Dictyostelium discoideum (Lam et al., 2008). Through random insertional mutagenesis, the authors showed that inactivation of the iplA gene, the only gene encoding an IP3R in this organism, prevented autophagic cell death (Lam et al., 2008). 
The stimulatory role of IP3R on starvation-induced autophagy has been recently shown (Decuypere et al., 2011b). The authors showed that the $\mathrm{Ca}^{2+}$ chelator BAPTA-AM as well as the IP3R inhibitor xestospongin $\mathrm{B}$ abolished starvation induced increase in LC3 lipidation and GFP-LC3-puncta formation. Moreover, starvation lead to IP3R sensitization through increased Beclin1 binding to the IP3R (Decuypere et al., 2011b).

To date, most reports on IP3R-dependent regulation of autophagy suggest inhibitory role for IP3R toward autophagy (Parys et al., 2012).

Thus, lithium $\left(\mathrm{Li}^{+}\right)$was found to induce mTOR independent autophagy through inhibition of inositol monophosphatase and further decrease in IP3 levels (Sarkar et al., 2005). Consistently, another study demonstrated that IP3R inhibitor xestospongin (XeB) or IP3R knockdown induced autophagy in HeLa cells (Criollo et al., 2007). One of the mechanisms, by which XeB and starvation induce autophagy was proposed by Vicencio et al. (2009). The authors suggested that xestospongin B and nutrient starvation disrupt a molecular complex formed by the IP3R, Beclin 1 and Bcl-2, and presented evidence that the IP3R represses autophagy through Bcl-2-mediated binding of Beclin 1, thus suggesting $\mathrm{Ca}^{2+}$-independent mechanism (Vicencio et al., 2009).

As three IP3R isoforms exist, some groups studied the impact of IP3R on autophagy in the triple IP3R-deficient DT40 cells (Cardenas et al., 2010; Khan and Joseph, 2010). These cells demonstrate higher basal autophagy levels, compared to wild-type. Interestingly, expression of IP3R3, but not of ryanodine receptor type 2, rescued elevated autophagy in these cells (Cardenas et al., 2010). In contrast, expression of $\mathrm{Ca}^{2+}$ impermeable mutant D2550A-IP3R3 failed to suppress constitutive autophagy, suggesting a necessity of the $\mathrm{Ca}^{2+}$-release activity for IP3R. The authors proposed the mechanism in which constitutive IP3R mediated $\mathrm{Ca}^{2+}$ release and uptake of this $\mathrm{Ca}^{2+}$ by mitochondria is fundamentally required to maintain mitochondrial bioenergetics and ATP production in resting cells thereby suppressing autophagy. Absence of this $\mathrm{Ca}^{2+}$ transfer results in inhibition of pyruvate dehydrogenase and activation of AMPK, which activates prosurvival macroautophagy in mTOR independent manner (Cardenas et al., 2010).

Along with IP3R some other calcium permeable channels were shown to be involved in autophagy regulation. Among them, TRPML1, also known as mucolipin-1, ubiquitously expressed TRP channel primarily localized to the late endosomal and lysosomal compartments (Zeevi et al., 2009; Cheng et al., 2010). Direct patch-clamp of enlarged lysosomes revealed that TRPML1 is a $\mathrm{Ca}^{2+}$ permeable channel (Dong et al., 2008). The main physiological function of TRPML1 channel is considered to serve as a late endosomal/lysosomal $\mathrm{Ca}^{2+}$ release channel. Lossof-function mutations in the human TRPML1 gene result in mucolipidosis type IV, a neurodegenerative lysosomal storage disorder characterized by mental retardation and retinal degeneration (Bach, 2001; Altarescu et al., 2002). Fibroblasts from mucolipidosis type IV patients exhibit enlarged vacuoles with accumulated lipids and acid mucopolysacharides, suggesting the role for TRPML1 in trafficking of proteins and lipids (Riedel et al., 1985; Goldin et al., 1999; Slaugenhaupt et al., 1999). Loss of TRPML1 has been shown to be accompanied by impairment in the lysosomal $\mathrm{pH}$, accumulation of autophagosomes and abnormal mitochondria, accumulation and aggregation of p62 and ubiquitin proteins, all of which suggested a defective autophagy (Jennings et al., 2006; Soyombo et al., 2006; Vergarajauregui et al., 2008; Curcio-Morelli et al., 2010). Indeed, several studies have proposed TRPML1 as autophagy regulator (Vergarajauregui et al., 2008; Venugopal et al., 2009; Curcio-Morelli et al., 2010; Wong et al., 2012a; Venkatachalam et al., 2013). Vergarajauregui et al. showed that accumulation of autophagosomes in TRPML1deficient fibroblasts obtained from mucolipidosis type IV patients was due to increased Beclin-1 dependent autophagosome formation and delayed fusion of autophagosomes with late endosomes/lysosomes. The authors claimed that TRPML1 is necessary for efficient fusion of both autophagosomes and late endosomes with lysosomes although it is not clear if the $\mathrm{Ca}^{2+}$-channel function of the TRPML1 is essential here (Vergarajauregui et al., 2008). In another study, group of S. Slaugenhaupt showed that CMA is impaired in mucolipidosis type IV fibroblasts (Venugopal et al., 2009). The authors showed that TRPML1 directly interacts with Hsc70 and Hsp40, members of molecular chaperone complex required for CMA, and hypothesized that this interaction may be required for intralysosomal Hsc70 to facilitate the translocation of CMA substrate proteins across the lysosomal membrane. The authors also speculated that TRPML1 channel activity is required for CMA (Venugopal et al., 2009). In 2010 same group investigated macroautophagy in neurons isolated from cerebellum of TRPML1 ${ }^{-/-}$mouse embryos (Curcio-Morelli et al., 2010). These cells displayed higher levels of basal autophagy markers compared to wild-type ones. In addition, LC3-II clearance was affected in these cells, suggesting impairment of lysosomal function. However, the link between observed defects in autophagy and functionality of TRPML1 as a $\mathrm{Ca}^{2+}$ permeable channel is missing. Recently, Wong et al showed that Drosophila TRPML is required for TORC1 activation (Wong et al., 2012a). Authors demonstrated defects in amphisomes/lysosomes fusion and elevated late endosomal/lysosomal $\mathrm{Ca}^{2+}$ levels in flies lacking TRPML1. Authors also showed decreased TORC1 activity and increased induction of autophagy in TRPML1 ${ }^{-}$mutants. Moreover, authors suggested that TORC1 regulates the subcellular localization of TRPML1. Thus, this study points out to TRPML1 as a $\mathrm{Ca}^{2+}$ channel present in amphisomes which releases luminal $\mathrm{Ca}^{2+}$ to facilitate $\mathrm{Ca}^{2+}$-dependent fusion of amphisomes with lysosomes (Wong et al., 2012a).

In addition to TRPML1, another member of mucolipin family, TRPML3 has been shown to be involved in autophagy regulation. In contrast to TRPML1, TRPML3 exhibits more restrictive tissue distribution, and is primarily localized to early as well as late endosomes/lysosomes and less to the plasma membrane (Zeevi et al., 2009; Cheng et al., 2010).

It has been shown that overexpression of TRPML3 leads to increased autophagy in HeLa cells (Kim et al., 2009). Moreover, TRPML3 is recruited to autophagosomes upon induction of autophagy. Additionally, expression of dominant negative mutant TRPML3 (D458K) or knockdown of endogenous TRPML3 by siRNA reduces autophagy. Thus, it has been proposed that TRPML3 provides $\mathrm{Ca}^{2+}$ that is required for fusion and fission events in autophagy (Kim et al., 2009). Further, 
heteromultimerization of TRPML channels was shown to affect autophagy (Zeevi et al., 2010).

Also TRPV1 was proposed to regulate autophagy in thymocytes (Farfariello et al., 2012). The authors showed that capsaicin, an activator of TRPV1, induce Beclin-1 dependent accumulation of LC3-II protein. This effect can be antagonized by capsazepine, a blocker of TRPV1 and compound C, an AMPK inhibitor, suggesting AMPK involvement. The authors proposed that capsaicin induced autophagy is calcium dependent, as cotreatment with EDTA markedly reduced LC3-II accumulation. Moreover, it was shown that capsaicin induces accumulation of ATG4C and triggers its oxidation in a ROS-dependent manner, thus regulating LC3 lipidation levels (Farfariello et al., 2012). However, capsaicin was shown to have TRPV1-independent effects, such as inhibition of voltage-gated calcium channels (Hagenacker et al., 2005), cancer cell growth inhibition and apoptosis induction (Mori et al., 2006; Chow et al., 2007). Additionally, upon prolonged exposure to capsaicin, TRPV1 desensitization occurs and its activity decreases (Caterina et al., 1997). Thus, additional experiments using more specific agonists and antagonists as well as siRNA knockdown are needed to confirm the role of TRPV1 in autophagy regulation. It would be interesting as well to compare the effect of capsaicin on autophagy in TRPV1-expressing and TRPV1-null cells.

Some ion channels, which do not belong to the family of TRP channels, were also proposed to regulate autophagy. Williams et al. found that L-type calcium channels antagonists, namely verapamil, loperamide, nimodipine, nitrendipine and amiodarone induce mTOR-independent autophagy (Williams et al., 2008). Conversely, the L-type $\mathrm{Ca}^{2+}$ channel agonist ( \pm )-BAY K 8644 that increases cytosolic $\mathrm{Ca}^{2+}$ levels, inhibits autophagy. Authors demonstrated that elevated cytosolic $\mathrm{Ca}^{2+}$, presumably due to activity of L-type calcium channels on the plasma membrane, can activate calpains, a family of $\mathrm{Ca}^{2+}$-dependent cysteine proteases, which cleave and activate the $\alpha$-subunit of heterotrimeric $\mathrm{G}$ proteins $\mathrm{G}_{s} \alpha . \mathrm{G}_{s} \alpha$ activation, in turn, increases adenylyl cyclase activity leading to increase in cAMP levels. Next, elevated intracellular cAMP levels negatively regulate autophagy by promoting IP3 production via cAMP-Epac-Rap2B-PLC- $\varepsilon$ pathway. Finally, IP3, via IP3R influence cytosolic $\mathrm{Ca}^{2+}$ levels, which can again activate calpains, thus creating a potential positive feedback loop for autophagy inhibition (Williams et al., 2008). Again, it is important to mention that although several different L-type calcium channel inhibitors as well as agonist were used in the study, the data showing the effect of siRNA mediated knockdown of L-type calcium channels and/or channel-dead mutants on autophagy are missing. It would be interesting as well to check the effect of these inhibitors on "negative control" cells lacking L-type calcium channels. In addition, verapamil is known to passively diffuse into the lysosome, where it becomes protonated and could cause an increase in lysosomal pH (Lemieux et al., 2004). This could lead to the inhibition of lysosome function and thus block fusion with the autophagosome.

Two-pore channels (TPC) have been also proposed to regulate autophagy (Pereira et al., 2011; Gomez-Suaga et al., 2012). Mammalian TPC family comprise two members TPC1 and TPC2, widely expressed in humans and localized intracellularly on endolysosomes, with TPC2 being specifically targeted to lysosomes. Several groups proposed TPC as a mediator of endolysosomal calcium release in response to the elevation of the second messenger, nicotinic acid adenine dinucleotide phosphate (NAADP) (Calcraft et al., 2009; Galione et al., 2009). Recently Pereira et al. demonstrated that NAADP stimulates autophagy via TPCs in rat astrocytes (Pereira et al., 2011). The authors showed that NAADP mediated increase in the number of LC3GFP puncta was reduced in cells, transfected with dominant negative TPC2 L265P construct, suggesting the importance of TPC2 for autophagy (Pereira et al., 2011). TPC2 channel has been also proposed to be involved in LRRK2 induced autophagy (Gomez-Suaga et al., 2012).

The MCU that was recently identified as a channel responsible for mitochondrial $\mathrm{Ca}^{2+}$ uptake (Baughman et al., 2011; De Stefani et al., 2011) has been demonstrated to have the role in autophagy regulation. Indeed, Cardenas et al. showed that the uniporter inhibitor Ru360 inhibited cell $\mathrm{O}_{2}$ consumption rate, activated AMPK, and induced autophagy (Cardenas et al., 2010). In line with these data, MCUR1(mitochondrial calcium uniporter regulator 1) was shown to regulate autophagy (Mallilankaraman et al., 2012). MCUR1 represents an integral membrane protein that is required for MCU-dependent mitochondrial $\mathrm{Ca}^{2+}$ uptake. Knockdown of MCUR1 in HeLa and HEK293T cells reduced cell $\mathrm{O}_{2}$ consumption rate, activated AMPK, and induced macroautophagy (Mallilankaraman et al., 2012). Importantly, stable knockdown of MCU in HeLa cells elicited essentially the same effects, confirming the regulatory role for MCU toward autophagy (Mallilankaraman et al., 2012).

MPTP has been also suggested to be implicated in autophagy regulation. Elmore et al. proposed that mitochondrial permeability transition (MPT) initiates autophagy in rat hepatocytes. Although the mechanism by which the MPT signals autophagic sequestration was not investigated in this work, the authors hypothesized that factors released from the mitochondrial intermembrane space as a consequence of MPT could stimulate autophagy (Elmore et al., 2001). It is not clear if the $\mathrm{Ca}^{2+}$. release channel function of the MPTP is essential here as well. A functional MPTP was also shown to be required for starvationinduced mitochondrial autophagy (Carreira et al., 2010). The authors demonstrated that starvation induced mitochondrial depolarization in cardiac cells. This depolarization was prevented by cyclosporin A (MPT inhibitor). Further, the authors showed that cyclophilin D a component of the MPTP, is required for mitochondrial removal by starvation-induced autophagy. Interestingly, cardiomyocytes from cyclophilin D deficient mice failed to upregulate autophagy in response to nutrient deprivation, suggesting that MPTP is essential here (Carreira et al., 2010). Again the role of calcium and the importance of calcium permeability for MPTP in the regulation of autophagy were not assessed in this study.

\section{POTENTIAL NEW CANDIDATES FOR AUTOPHAGY REGULATION IN CANCER TREATMENT}

Aside from ion channels, described above, all the other calcium permeable channels could potentially be involved in autophagy regulation, as they contribute to the changes in cytosolic calcium 
levels. Here, we will provide several hypotheses for autophagy regulation by some of the calcium permeable channels that have not been shown to be directly involved in autophagy regulation. Further, we will propose the possible link between calcium permeable channels, autophagy and cancer progression and therapeutic response. Considering both physiological roles as well as cellular localization we selected several calcium permeable channels, which in our opinion could have an impact on autophagy.

TRPML2 channel, a member of the mucolipin family, has been shown to localize to late and recycling endosomes as well as lysosomes (Zeevi et al., 2009; Cheng et al., 2010). Recent study claimed that TRPML2 does not appear to play a role in starvation-induced autophagy (Zeevi et al., 2010). However, TRPML2 knockdown was demonstrated to induce lysosomal inclusions accumulation in HEK cells (Zeevi et al., 2009). This fact along with the endolysosomal distribution of TRPML2 indicates the potential role of TRPML2 in the regulation of basal as well as other types of autophagy.

TRPM2 is known as a chanzyme, combining two functions: of an ion channel and an enzyme, since the C-terminal of TRPM2 contains enzymatically active adenosine diphosphoribose (ADPR) hydrolase domain (Sumoza-Toledo and Penner, 2011). TRPM2 has been shown to be activated and regulated by variety of stimuli including $\mathrm{ADPR}, \mathrm{H}_{2} \mathrm{O}_{2}, \mathrm{NAADP}, \mathrm{pH}$, and cytosolic calcium. It is involved in numerous physiological processes, such as production of cytokines, insulin secretion, oxidative stress, apoptosis (Jiang et al., 2010). TRPM2 functions as a $\mathrm{Ca}^{2+}$-permeable channel on the cell surface, but recently TRPM2 has been shown to be also localized intracellularly on the late endosomal and lysosomal membranes where it functions as a lysosomal $\mathrm{Ca}^{2+}$ release channel (Lange et al., 2009). Thus, it can possibly affect autophagy in the same manner as TRPML and TPC channels. Interesting that both $\mathrm{Ca}^{2+}$-entry and $\mathrm{Ca}^{2+}$-release channel functions of TRPM2 were shown to be important in $\mathrm{H}_{2} \mathrm{O}_{2}$-induced beta-cell death (Lange et al., 2009). Further, $\mathrm{H}_{2} \mathrm{O}_{2}$ is a known activator of autophagy (Chen et al., 2008). Thus, potentially TRPM2 could be involved in $\mathrm{H}_{2} \mathrm{O}_{2}$-induced autophagy.

Another interesting candidate is the cold receptor TRPM8, which is found in sensory neurons, where it constitutes the principal detector of cold $\left(<\sim 28^{\circ} \mathrm{C}\right)$ (Bautista et al., 2007). In addition to its role as plasmalemmal $\mathrm{Ca}^{2+}$ channel, TRPM8 could function as intracellular $\mathrm{Ca}^{2+}$-release channel on the ER membrane (Zhang and Barritt, 2004; Thebault et al., 2005). Initially, TRPM8 was cloned from the human prostate as prostate-specific gene, which is upregulated in malignant tissues (Tsavaler et al., 2001). The role of TRPM8 in cancer was extensively studied in recent years, and published data suggest that TRPM8 could be involved in proliferation, differentiation and apoptosis in cancer cells (Zhang and Barritt, 2004; Thebault et al., 2005). Given the localization of TRPM8 on ER, it would be interesting to study the possible autophagy regulation by TRPM8-mediated $\mathrm{Ca}^{2+}$ release from the ER. The potential mechanisms could be the same as for IP3 receptor.

It is worth to note that TRPV1 channel, discussed above, has also been found to be expressed intracellularly at the ER and trans-Golgi network (Turner et al., 2003), so apart from the autophagy modulating mechanism provided above, TRPV1 could also be involved in another autophagy related signaling pathways.

TRPP2, the product of the gene mutated in autosomal dominant polycystic kidney disease (ADPKD), is another possible candidate for autophagy regulation. It is widely expressed, with a highest level in the kidney, and primarily localized in cilia, where it seems to function as a mechanosensor involved in the nodal ciliary movement (Delmas et al., 2004). TRPP2 might function as a plasma membrane calcium-permeable channel (when interacting with TRPP1) or as a calcium release channel located in the ER (Hanaoka et al., 2000; Cahalan, 2002; Koulen et al., 2002). Interesting, TRPP2 was shown to function as a calcium-activated intracellular calcium release channel-property reminiscent of IP3 receptors and ryanodine receptors (Koulen et al., 2002). Thus, potentially TRPP2 could regulate autophagy in a way similar to IP3R.

Interesting, although ryanodine receptor (RyR) constitutes the major cellular mediator of calcium-induced calcium release, the data on its role in autophagy is very scarce. As it was mentioned above, overexpression of ryanodine receptor type 2 in triple IP3Rdeficient DT40 cells was without effect on constitutive autophagy (Cardenas et al., 2010). Despite this, we believe that more experiments are required to unravel the role of RyR in autophagy regulation.

The next candidate, TRPV2, is a $\mathrm{Ca}^{2+}$ permeable non-selective cationic channel, which has been found to be activated by noxious heat $\left(>50^{\circ} \mathrm{C}\right)$, growth factors (i.e., IGF) and stretch (Caterina et al., 1999; Kanzaki et al., 1999; Muraki et al., 2003). It was shown that insulin induced translocation and insertion of TRPV2 into the plasma membrane in a PI3K-dependent manner (Aoyagi et al., 2010). Recent studies revealed the role for TRPV2 in promoting prostate cancer migration and progression to androgen resistance (Monet et al., 2010). Interestingly, Saito et al. demonstrated the function of 2-APB-activated and Rutenium Redinhibited calcium-permeable ion channel in early endosomes (Saito et al., 2007). The authors reported that this channel has similar pharmacology to that of TRPV2. As early endosomes, and fusion of autophagosomes with functional early endosomes have been shown to be essential for autophagy (Razi et al., 2009), we hypothesize that TRPV2, which apparently forms early endosomal $\mathrm{Ca}^{2+}$-release channel, could be involved in autophagy where it may regulate fusion between autophagosomes and early endosomes. Function on the plasma membrane as well as dependence on PI3K suggest possible complex role in autophagy regulation.

ORAI1 (the calcium release-activated calcium channel protein 1) which constitutes a major molecular component of storeoperated calcium (SOC) channels (Hewavitharana et al., 2007) also represents an attractive candidate for autophagy regulation. Recently, Abdelmohsen et al. reported that microRNA miR-519 stimulates autophagy through the downregulation of ORAI1 and ATP2C1 proteins, increase in the cytosolic $\mathrm{Ca}^{2+}$ levels, activation of $\mathrm{Ca}^{2+}$-activated calmodulin kinase II (CaMKII) as well as glycogen synthase kinase $3 \beta$ (GSK3 $\beta$ ) and subsequent p21 upregulation (Abdelmohsen et al., 2012). However, the direct link between autophagy stimulation and functionality of ORAI1 as a $\mathrm{Ca}^{2+}$ permeable channel is missing. Thus, additional experiments using specific agonists and antagonists as well as siRNA 


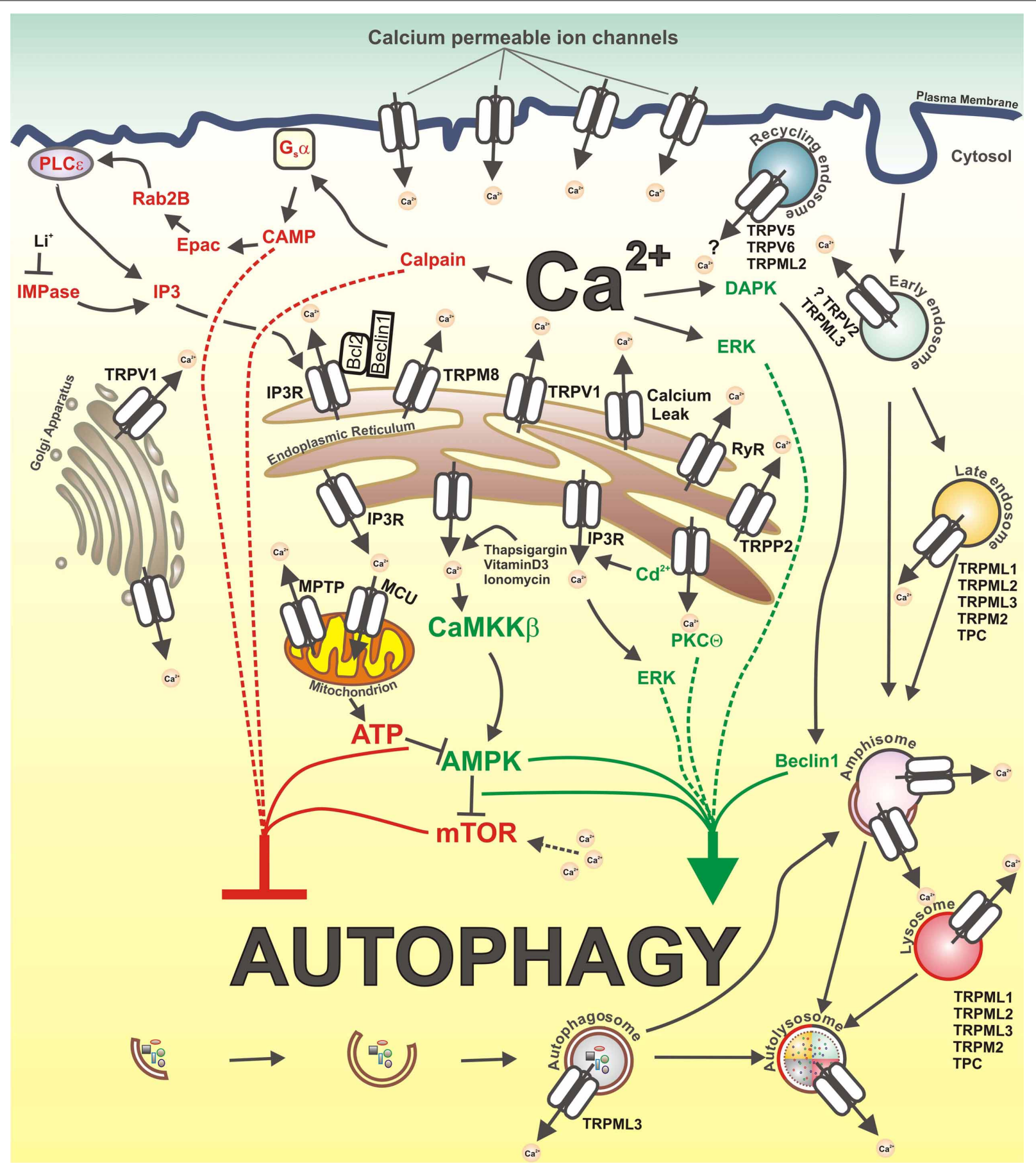

FIGURE 1 | Calcium and calcium-permeable channels in the control of autophagy. Inhibitory and stimulatory actions of $\mathrm{Ca}^{2+}$ on autophagy as well as calcium-permeable channels that could be potentially involved in autophagy regulation are depicted. $\mathrm{Ca}^{2+}$ mobilizing agents, such as vitamin D3, thapsigargin and ionomycin, lead to increase in cytosolic $\mathrm{Ca}^{2+}$ $\left(\left[\mathrm{Ca}^{2+}\right]_{\text {cyt }}\right)$ concentration and subsequent activation of CAMKK-beta, followed by AMPK-dependent mTOR inhibition and autophagy stimulation. ER-stress induced elevation of $\left[\mathrm{Ca}^{2+}\right]_{\text {cyt }}$ levels activate PKCtheta which stimulates autophagy. Additionally, increased $\left[\mathrm{Ca}^{2+}\right]_{\mathrm{cyt}}$ induce activation of DAPK, which phosphorylates Beclin1, thereby promoting its dissociation from $\mathrm{BCl}-\mathrm{X}_{L}$ and $\mathrm{Bcl}-2$ inhibitory proteins, and thus stimulate autophagy. Cadmium induces autophagy through elevation of cytosolic $\mathrm{Ca}^{2+}$ via IP3R and subsequent ERK activation. In contrast, constitutive IP3R mediated $\mathrm{Ca}^{2+}$ release to mitochondria maintains ATP production and AMPK inhibition, thereby suppressing autophagy. The inhibition of IMPase by $\mathrm{Li}^{+}$ causes a decrease in IP3 levels and autophagy induction. Further,

IP3R-dependent $\mathrm{Ca}^{2+}$ release from the ER as well as amino acids-induced increase in $\left[\mathrm{Ca}^{2+}\right]_{c y t}$ maintain an elevated mTORC1 activity, thus inhibiting autophagy. In addition, IP3R represses autophagy through Bcl-2-mediated binding of Beclin1. Also, increased $\mathrm{Ca}^{2+}$ influx through L-type calcium channels on the plasma membrane activates calpains and consequently Gsalpha/Adenylyl cyclase/cAMP/Epac/Rap2B/PLC- $\varepsilon$ pathway which negatively regulates autophagy by promoting IP3 production, IP3R activation and $\mathrm{Ca}^{2+}$ release. 
knockdown of ORAI1 are needed to confirm its role in autophagy regulation.

A subset of other channels, found to be localized both on plasma membrane and intracellular vesicles (i.e., recycling endosomes), including TRPC3, TRPV6, and TRPV5, could also potentially modulate autophagy, although at present it's not clear if these channels are functional intracellularly (Dong et al., 2010; Toro et al., 2011). A graphic overview of the calcium-related mechanisms of autophagy regulation is presented in Figure 1.

Thus, available data strongly suggests that calcium permeable channels represent good candidates for autophagy regulation. Given that both autophagy and calcium-permeable ion channels have a role in cancer, this can be highly valuable in order to achieve specific outcomes in anti-cancer therapy. Ion channels could provide some advantages, when targeting autophagy in vivo for cancer treatment. Indeed, most ion channels are localized on cell surface, thus they can be subjected to antibody-based targeting that can be particularly useful in the case of channel upregulation in cancer. Moreover, anti-channel antibodies could be used as carriers for radionuclides, toxic molecules or nanoparticles, which can themselves affect autophagy and as such influence cell fate.

The growing number of studies pointing on the fact that inflammation increases the incidence of cancer (Mantovani et al., 2008). Autophagy has been linked to both cancer and inflammation, and is often defective in the inflammatory conditions (White et al., 2010). Among them, Crohn's disease and pancreatitis have been associated with an increased risk of colorectal and pancreatic cancers, respectively (Freeman, 2008; Raimondi et al., 2010). Accordingly, these pathological states are characterized by the accumulation of damaged organelles and polyubiquitinilated protein aggregates, ROS production and DNA damage, the factors that create a cancer-promoting environment (Gukovsky et al., 2012; Nguyen et al., 2013). Hence, this implies that functional autophagy stimulation, to eliminate dangerous garbage, may constitute an effective approach to cancer prevention. Interestingly, a number of calcium-permeable ion channels, including TRPV1, TRPV4, TRPA1, and TRPM8, were shown to be regulated by inflammatory mediators (Nilius et al., 2007; Kochukov et al., 2009; Zhang et al., 2012). Thus, these channels can represent potential targets to stimulate autophagy in inflammatory conditions in order to avert tumorigenesis initiation. Additionally, lysosomal dysfunctions have been reported in pancreatitis (Gukovsky et al., 2012), therefore it could be interesting to consider lysosomal ion channels as well.

On the other hand, in existing tumors autophagy may favor survival and progression. Thus, the possible anticancer therapy should be focused on autophagy inhibition. In this case,

\section{REFERENCES}

Abdelmohsen, K., Srikantan, S., Tominaga, K., Kang, M. J., Yaniv, Y., Martindale, J. L., et al. (2012). Growth inhibition by miR-519 via multiple p21-inducing pathways. Mol. Cell. Biol. 32, 2530-2548. doi: 10.1128/MCB.00510-12

Altarescu, G., Sun, M., Moore, D.

F., Smith, J. A., Wiggs, E. A.,
Solomon, B. I., et al. (2002). The neurogenetics of mucolipidosis type IV. Neurology 59, 306-313. doi: 10.1212/WNL.59.3.306

Amaravadi, R. K., Lippincott-Schwartz, J., Yin, X. M., Weiss, W. A., Takebe, N., Timmer, W., et al. (2011). Principles and current strategies for targeting autophagy for cancer treatment. Clin. Cancer Res.

considering calcium-permeable channels as a potential tool to target autophagy could also be useful. More specifically, as we discussed above, a number of calcium-permeable ion channels exhibit altered expression in cancer cells. For instance, TRPM8 is upregulated in androgen-dependent prostate cancer cells (Zhang and Barritt, 2004; Thebault et al., 2005). This could possibly influence intracellular calcium levels and consequently autophagy. Hence, targeting TRPM8 as well as another channels overexpressed in cancers could provide an additional control over autophagy, particularly during chemotherapy, and as such contribute to cancer treatment.

\section{CONCLUSIONS}

Calcium-permeable ion channels have emerged as important regulators of autophagy and the effect of such regulation most likely depends on $\mathrm{Ca}^{2+}$ signals in a spatially restricted subcellular domains. Apparently, such regulation can represent a fundamental mechanism of fine tuning the autophagy. However, the data concerning this subject is very limited, thus further studies are needed to understand the variety of mechanisms, by which calcium channels can influence autophagy.

Accumulated data proves that both calcium-permeable ion channels and autophagy are implicated in cancer initiation and progression as well as chemotherapy resistance. Paradoxically, autophagy has opposite roles in cancer, with both tumorigenesis suppressor action, in particular at the early stages of tumor initiation and cancer promotion effect resulting in tumor cell survival, chemotherapy resistance and cancer progression. Thus, it is important to unravel autophagy regulating pathways to most effectively target autophagy to cure cancer. Identification of the connections between calcium channels and autophagy could define a new strategy in cancer treatment, and identify useful tools and biomarkers for the elaboration of effective anti-cancer therapies. Moreover, as malfunction of autophagy has been linked to a wide range of human pathologies including liver disease, neurodegeneration, Crohn's disease and cancer, uncovering novel mechanisms of autophagy regulation by calcium permeable ion channels could have a broad impact on the "Autophagy" field and contribute to the developing of autophagy as a potential clinical approach to cure diseases.

\section{ACKNOWLEDGMENTS}

The authors acknowledge financial support from the INSERM, la Ligue Nationale Contre le Cancer, le Ministere de l'Education Nationale, the Region Nord/Pas-de-Calais. Artem Kondratskyi was supported by fellowship from FRM (Fondation de Recherche Medicale). Maya Yassine was a recipient of a $\mathrm{PhD}$ scholarship from Erasmus Mundus. Kateryna Kondratska is an IonTrac Project fellow.

17, 654-666. doi: 10.1158/10780432.CCR-10-2634

Amaravadi, R. K., Yu, D., Lum, J. J., Bui, T., Christophorou, M. A., Evan, G. I., et al. (2007). Autophagy inhibition enhances therapy-induced apoptosis in a Myc-induced model of lymphoma. J. Clin. Invest. 117, 326-336. doi: 10.1172/JCI2 8833
Aoyagi, K., Ohara-Imaizumi, M., Nishiwaki, C., Nakamichi, Y., and Nagamatsu, S. (2010). Insulin/phosphoinositide 3-kinase pathway accelerates the glucoseinduced first-phase insulin secretion through TrpV2 recruitment in pancreatic beta-cells. Biochem. J. 432, 375-386. doi: 10.1042/BJ201 00864 
Arico, S., Petiot, A., Bauvy, C., Dubbelhuis, P. F., Meijer, A. J., Codogno, P., et al. (2001). The tumor suppressor PTEN positively regulates macroautophagy by inhibiting the phosphatidylinositol 3-kinase/protein kinase B pathway. J. Biol. Chem. 276, 35243-35246. doi: $10.1074 / j b c . C 100319200$

Bach, G. (2001). Mucolipidosis type IV. Mol. Genet. Metab. 73, 197-203. doi: 10.1006/mgme.2001.3195

Baughman, J. M., Perocchi, F., Girgis, H. S., Plovanich, M., BelcherTimme, C. A., Sancak, Y., et al. (2011). Integrative genomics identifies MCU as an essential component of the mitochondrial calcium uniporter. Nature 476, 341-345. doi: 10.1038/nature10234

Bautista, D. M., Siemens, J., Glazer, J. M., Tsuruda, P. R., Basbaum, A. I., Stucky, C. L., et al. (2007). The menthol receptor TRPM8 is the principal detector of environmental cold. Nature 448, 204-208. doi: 10.1038/nature05910

Bernardi, P. (2013). The mitochondrial permeability transition pore: a mystery solved. Front. Physiol. 4:95. doi: 10.3389/fphys.2013.00095

Bernardi, P., and von Stockum, S. (2012). The permeability transition pore as a $\mathrm{Ca}(2+)$ release channel: new answers to an old question. Cell Calcium 52, 22-27. doi: 10.1016/j.ceca.2012.03.004

Berridge, M. J., Bootman, M. D., and Roderick, H. L. (2003). Calcium signalling: dynamics, homeostasis and remodelling. Nat. Rev. Mol. Cell Biol. 4, 517-529. doi: 10.1038/nrm1155

Berridge, M. J., Lipp, P., and Bootman, M. D. (2000). The versatility and universality of calcium signalling. Nat. Rev. Mol. Cell Biol. 1, 11-21. doi: 10.1038/35036035

Boehning, D., Patterson, R. L., and Snyder, S. H. (2004). Apoptosis and calcium: new roles for cytochrome $c$ and inositol 14 , 5-trisphosphate. Cell Cycle 3, 252-254.

Bultynck, G., Vermassen, E., Szlufcik, K., De Smet, P., Fissore, R. A., Callewaert, G., et al. (2003). Calcineurin and intracellular Ca2+release channels: regulation or association. Biochem. Biophys. Res. Commun. 311, 1181-1193. doi: 10.1016/j.bbrc.2003.08.084

Cahalan, M. D. (2002). The ins and outs of polycystin-2 as a calcium release channel. Nat. Cell Biol. 4, E56-E57. doi: 10.1038/ncb0302-e56

Calcraft, P. J., Ruas, M., Pan, Z., Cheng, X., Arredouani, A., Hao, X., et al. (2009). NAADP mobilizes calcium from acidic organelles through twopore channels. Nature 459, 596-600. doi: 10.1038/nature08030

Cardenas, C., and Foskett, J. K. (2012). Mitochondrial $\mathrm{Ca}(2+)$ signals in autophagy. Cell Calcium 52, 44-51. doi: 10.1016/j.ceca.2012.03.001

Cardenas, C., Miller, R. A., Smith, I., Bui, T., Molgo, J., Muller, M., et al. (2010). Essential regulation of cell bioenergetics by constitutive InsP3 receptor $\mathrm{Ca} 2+$ transfer to mitochondria. Cell 142, 270-283. doi: 10.1016/j.cell.2010.06.007

Carreira, R. S., Lee, Y., Ghochani, M., Gustafsson, A. B., and Gottlieb, R. A. (2010). Cyclophilin D is required for mitochondrial removal by autophagy in cardiac cells. Autophagy 6, 462-472. doi: 10.4161/auto.6.4.11553

Caterina, M. J., Rosen, T. A., Tominaga, M., Brake, A. J., and Julius, D. (1999). A capsaicin-receptor homologue with a high threshold for noxious heat. Nature 398, 436-441. doi: $10.1038 / 18906$

Caterina, M. J., Schumacher, M. A., Tominaga, M., Rosen, T. A., Levine, J. D., and Julius, D. (1997). The capsaicin receptor: a heat-activated ion channel in the pain pathway. Nature 389, 816-824. doi: 10.1038/39807

Chen, Y., and Klionsky, D. J. (2011). The regulation of autophagy - unanswered questions. J. Cell Sci. 124, 161-170. doi: 10.1242/jcs. 064576

Chen, Y., McMillan-Ward, E., Kong, J., Israels, S. J., and Gibson, S. B. (2008). Oxidative stress induces autophagic cell death independent of apoptosis in transformed and cancer cells. Cell Death Differ. 15, 171-182. doi: 10.1038/si.cdd. 4402233

Cheng, X., Shen, D., Samie, M. and $\mathrm{Xu}, \mathrm{H}$. (2010). Mucolipins: intracellular TRPML1-3 channels. FEBS Lett. 584, 2013-2021. doi 10.1016/j.febslet.2009.12.056

Cheong, H., Lu, C., Lindsten, T., and Thompson, C. B. (2012) Therapeutic targets in cancer cell metabolism and autophagy. Nat. Biotechnol. 30, 671-678. doi: 10.1038/nbt.2285

Choi, A. M., Ryter, S. W., and Levine, B. (2013). Autophagy in human health and disease. N.Engl. J. Med. 368, 651-662. doi: 10.1056/NEJMra1205406

Chow, J., Norng, M., Zhang, J., and Chai, J. (2007). TRPV6 mediates capsaicin-induced apoptosis in gastric cancer cells-Mechanisms behind a possible new "hot" cancer treatment. Biochim. Biophys. Acta 1773, 565-576. doi: 10.1016/j.bbamcr.2007.01.001
Clapham, D. E. (2007). SnapShot: mammalian TRP channels. Cell 129, 220.e1-220.e2. doi 10.1016/j.cell.2007.03.034

Criollo, A., Maiuri, M. C., Tasdemir, E., Vitale, I., Fiebig, A. A., Andrews, D., et al. (2007). Regulation of autophagy by the inositol trisphosphate receptor. Cell Death Differ. 14, 1029-1039. doi: 10.1038/sj.cdd.4402099

Curcio-Morelli, C., Charles, F. A., Micsenyi, M. C., Cao, Y., Venugopal, B., Browning, M. F., et al. (2010). Macroautophagy is defective in mucolipin-1-deficient mouse neurons. Neurobiol. Dis. 40, 370-377. doi: 10.1016/j.nbd.2010.06.010

Curry, M. C., Peters, A. A., Kenny, P. A., Roberts-Thomson, S. J., and Monteith, G. R. (2013) Mitochondrial calcium uniporter silencing potentiates caspase-independent cell death in MDA-MB-231 breast cancer cells. Biochem. Biophys. Res. Commun. 434, 695-700. doi: 10.1016/j.bbrc.2013.04.015

Decuypere, J. P., Bultynck, G., and Parys, J. B. (2011a). A dual role for $\mathrm{Ca}(2+)$ in autophagy regulation. Cell Calcium 50, 242-250. doi: 10.1016/j.ceca.2011.04.001

Decuypere, J. P., Welkenhuyzen, K., Luyten, T., Ponsaerts, R. Dewaele, M., Molgo, J., et al. (2011b). Ins(1 4, 5)P3 receptormediated $\mathrm{Ca} 2+$ signaling and autophagy induction are interrelated. Autophagy 7, 1472-1489. doi: 10.4161/auto.7.12.17909

Degenhardt, K., Mathew, R., Beaudoin, B., Bray, K., Anderson, D., Chen, G., et al. (2006). Autophagy promotes tumor cell survival and restricts necrosis, inflammation, and tumorigenesis. Cancer Cell 10, 51-64. doi: 10.1016/j.ccr.2006.06.001

Delmas, P., Padilla, F., Osorio, N., Coste, B., Raoux, M., and Crest, M. (2004). Polycystins, calcium signaling, and human diseases. Biochem. Biophys. Res. Commun. 322, 1374-1383. doi 10.1016/j.bbrc.2004.08.044

De Stefani, D., Raffaello, A., Teardo, E., Szabo, I., and Rizzuto, R. (2011). A forty-kilodalton protein of the inner membrane is the mitochondrial calcium uniporter. Nature 476 336-340. doi: 10.1038/nature10230

Dong, X. P., Cheng, X., Mills, E., Delling, M., Wang, F., Kurz, T., et al. (2008). The type IV mucolipidosisassociated protein TRPML1 is an endolysosomal iron release channel. Nature 455, 992-996. doi: 10.1038/nature07311
Dong, X. P., Wang, X., and Xu, H. (2010). TRP channels of intracellular membranes. J. Neurochem. 113, 313-328. doi: 10.1111/j.14714159.2010.06626.x

Dubois, C., Vanden Abeele, F., and Prevarskaya, N. (2013). Targeting apoptosis by the remodelling of calcium-transporting proteins in cancerogenesis. FEBS J. doi: 10.1111/febs.12246. [Epub ahead of print].

Elmore, S. P., Qian, T., Grissom, S. F., and Lemasters, J. J. (2001). The mitochondrial permeability transition initiates autophagy in rat hepatocytes. FASEB J. 15, 2286-2287. doi: 10.1096/fj.01-0206fje

Farfariello, V., Amantini, C., and Santoni, G. (2012). Transient receptor potential vanilloid 1 activation induces autophagy in thymocytes through ROSregulated AMPK and $\operatorname{Atg} 4 \mathrm{C}$ pathways. J. Leukoc. Biol. 92, 421-431. doi: 10.1189/jlb.0312123

Feng, Z., Zhang, H., Levine, A. J., and Jin, S. (2005). The coordinate regulation of the p53 and mTOR pathways in cells. Proc. Natl. Acad. Sci. U.S.A. 102, 8204-8209. doi: 10.1073/pnas.0502857102

Flourakis, M., Lehen'kyi, V., Beck, B., Raphael, M., Vandenberghe, M., Abeele, F. V., et al. (2010). Orail contributes to the establishment of an apoptosis-resistant phenotype in prostate cancer cells. Cell Death Dis. 1, e75. doi: 10.1038/cddis.2010.52

Flourakis, M., and Prevarskaya, N. (2009). Insights into Ca2+ homeostasis of advanced prostate cancer cells. Biochim. Biophys. Acta 1793, 1105-1109. doi: 10.1016/j.bbamcr.2009.01.009

Freeman, H. J. (2008). Colorectal cancer risk in Crohn's disease. World J. Gastroenterol. 14, 1810-1811. doi: 10.3748/wig. 14.1810

Galione, A., Evans, A. M., Ma, J., Parrington, J., Arredouani, A., Cheng, X., et al. (2009). The acid test: the discovery of two-pore channels (TPCs) as NAADP-gated endolysosomal $\mathrm{Ca}(2+)$ release channels. Pflugers Arch. 458, 869-876. doi: 10.1007/s00424-009-0682-y

Gao, W., Ding, W. X., Stolz, D. B., and Yin, X. M. (2008). Induction of macroautophagy by exogenously introduced calcium. Autophagy 4, 754-761.

Geng, J., and Klionsky, D. J. (2008). The Atg8 and Atg12 ubiquitin-like conjugation systems in macroautophagy.'Protein modifications: beyond the usual suspects' review series. EMBO Rep. 9, 859-864. doi: 10.1038/embor.2008.163 
Goldin, E., Cooney, A., Kaneski, C. R., Brady, R. O., and Schiffmann, R. (1999). Mucolipidosis IV consists of one complementation group. Proc. Natl. Acad. Sci. U.S.A. 96, 8562-8566. doi: 10.1073/pnas.96.15.8562

Gomez-Suaga, P., Luzon-Toro, B., Churamani, D., Zhang, L., BloorYoung, D., Patel, S., et al. (2012). Leucine-rich repeat kinase 2 regulates autophagy through a calcium-dependent pathway involving NAADP. Hum. Mol. Genet. 21, 511-525. doi: 10.1093/hmg/ ddr481

Gordon, P. B., Holen, I., Fosse, M., Rotnes, J. S., and Seglen, P. O. (1993). Dependence of hepatocytic autophagy on intracellularly sequestered calcium. J. Biol. Chem. 268, 26107-26112.

Gukovsky, I., Pandol, S. J., Mareninova, O. A., Shalbueva, N., Jia, W., and Gukovskaya, A. S. (2012). Impaired autophagy and organellar dysfunction in pancreatitis. J. Gastroenterol. Hepatol. 27(Suppl. 2), 27-32. doi: 10.1111/j.1440-1746.2011.07004.x

Gulati, P., Gaspers, L. D., Dann, S. G., Joaquin, M., Nobukuni, T., Natt, F., et al. (2008). Amino acids activate mTOR complex 1 via $\mathrm{Ca} 2+/ \mathrm{CaM}$ signaling to hVps34. Cell Metab. 7, 456-465. doi: 10.1016/j.cmet.2008.03.002

Guo, X. L., Li, D., Hu, F., Song, J. R., Zhang, S. S., Deng, W. J., et al. (2012). Targeting autophagy potentiates chemotherapy-induced apoptosis and proliferation inhibition in hepatocarcinoma cells. Cancer Lett. 320, 171-179. doi: 10.1016/j.canlet.2012.03.002

Hagenacker, T., Splettstoesser, F., Greffrath, W., Treede, R. D., and Busselberg, D. (2005). Capsaicin differentially modulates voltageactivated calcium channel currents in dorsal root ganglion neurones of rats. Brain Res. 1062, 74-85. doi: 10.1016/j.brainres.2005.09.033

Hajnoczky, G., Csordas, G., Madesh, M., and Pacher, P. (2000). Control of apoptosis by IP(3) and ryanodine receptor driven calcium signals. Cell Calcium 28, 349-363. doi: 10.1054/ceca.2000.0169

Hanaoka, K., Qian, F., Boletta, A., Bhunia, A. K., Piontek, K., Tsiokas, L., et al. (2000). Co-assembly of polycystin-1 and -2 produces unique cation-permeable currents. Nature 408, 990-994. doi: $10.1038 / 35050128$

He, C., and Levine, B. (2010). The Beclin 1 interactome. Curr. Opin. Cell Biol. 22, 140-149. doi: 10.1016/j.ceb.2010.01.001
Hewavitharana, T., Deng, X., Soboloff, J., and Gill, D. L. (2007). Role of STIM and Orai proteins in the store-operated calcium signaling pathway. Cell Calcium 42, 173-182. doi: 10.1016/j.ceca.2007.03.009

Hoyer-Hansen, M., Bastholm, L., Szyniarowski, P., Campanella, M., Szabadkai, G., Farkas, T., et al. (2007). Control of macroautophagy by calcium, calmodulin-dependent kinase kinase-beta, and Bcl2. Mol. Cell 25, 193-205. doi 10.1016/j.molcel.2006.12.009

Hsu, K. F., Wu, C. L., Huang, S. C., Wu, C. M., Hsiao, J. R., Yo, Y. T., et al. (2009). Cathepsin L mediates resveratrol-induced autophagy and apoptotic cell death in cervical cancer cells. Autophagy 5, 451-460. doi: 10.4161/auto.5.4.7666

Inbal, B., Bialik, S., Sabanay, I., Shani, G., and Kimchi, A. (2002). DAP kinase and DRP-1 mediate membrane blebbing and the formation of autophagic vesicles during programmed cell death J. Cell Biol. 157, 455-468. doi: 10.1083/jcb.200109094

Ito, H., Daido, S., Kanzawa, T., Kondo, S., and Kondo, Y. (2005). Radiationinduced autophagy is associated with LC3 and its inhibition sensitizes malignant glioma cells. Int. J. Oncol. 26, 1401-1410.

Jennings, J. J. Jr., Zhu, J. H., Rbaibi, Y., Luo, X., Chu, C. T., and Kiselyov, K. (2006). Mitochondrial aberrations in mucolipidosis Type, I. V. J. Biol. Chem. 281, 39041-39050. doi: 10.1074/jbc.M607982200

Jiang, L. H., Yang, W., Zou, J., and Beech, D. J. (2010). TRPM2 channel properties, functions and therapeutic potentials. Expert Opin. Ther. Targets 14, 973-988. doi: 10.1517/14728222.2010.510135

Kanzaki, M., Zhang, Y. Q., Mashima H., Li, L., Shibata, H., and Kojima, I. (1999). Translocation of a calciumpermeable cation channel induced by insulin-like growth factor-I. Nat. Cell Biol. 1, 165-170. doi: 10.1038/11086

Khan, M. T., and Joseph, S. K. (2010). Role of inositol trisphosphate receptors in autophagy in DT40 cells. J. Biol. Chem. 285, 16912-16920. doi: 10.1074/jbc.M110.114207

Kim, H. J., Soyombo, A. A., TjonKon-Sang, S., So, I., and Muallem, S. (2009). The $\mathrm{Ca}(2+)$ channel TRPML3 regulates membrane trafficking and autophagy. Traffic 10, 1157-1167. doi: 10.1111/j.1600-0854.2009.00924.x

Kim, J., Kundu, M., Viollet, B., and Guan, K. L. (2011). AMPK and mTOR regulate autophagy through direct phosphorylation of Ulk1. Nat. Cell Biol. 13, 132-141. doi $10.1038 /$ ncb2152

Kimura, T., Takabatake, Y., Takahashi, A., and Isaka, Y. (2013) Chloroquine in cancer therapy: a double-edged sword of autophagy. Cancer Res. 73, 3-7. doi: 10.1158/0008-5472.CAN-12-2464

Klionsky, D. J. (2005). The molecular machinery of autophagy: unanswered questions. J. Cell Sci. 118, 7-18. doi: 10.1242 /jcs.01620

Klionsky, D. J., Abdalla, F. C. Abeliovich, H., Abraham, R. T. Acevedo-Arozena, A., Adeli, K., et al. (2012). Guidelines for the use and interpretation of assays for monitoring autophagy. Autophagy 8, 445-544. doi: 10.4161/auto.19496

Kochukov, M. Y., McNearney, T. A., Yin, H., Zhang, L., Ma, F., Ponomareva, L., et al. (2009). Tumor necrosis factor-alpha (TNFalpha) enhances functional thermal and chemical responses of TRP cation channels in human synoviocytes. Mol. Pain 5, 49. doi: 10.1186/1744-8069-5-49

Kondo, Y., Kanzawa, T., Sawaya, R. and Kondo, S. (2005). The role of autophagy in cancer development and response to therapy. Nat. Rev. Cancer 5, 726-734. doi: 10.1038/nrc1692

Koulen, P., Cai, Y., Geng, L., Maeda, Y., Nishimura, S., Witzgall, R., et al. (2002). Polycystin-2 is an intracellular calcium release channel. Nat. Cell Biol. 4, 191-197. doi: 10.1038/ncb754

Kroemer, G., Marino, G., and Levine, B. (2010). Autophagy and the integrated stress response. Mol. Cell 40, 280-293. doi 10.1016/j.molcel.2010.09.023

Lam, D., Kosta, A., Luciani, M. F., and Golstein, P. (2008). The inositol 14 , 5-trisphosphate receptor is required to signal autophagic cell death. Mol. Biol. Cell 19, 691-700. doi: 10.1091/mbc.E07-08-0823

Lamoureux, F., and Zoubeidi, A. (2013). Dual inhibition of autophagy and the AKT pathway in prostate cancer. Autophagy 9 , 1119-1120. doi: 10.4161/auto.24921

Lange, I., Yamamoto, S., PartidaSanchez, S., Mori, Y., Fleig, A., and Penner, R. (2009). TRPM2 functions as a lysosomal Ca2+-release channel in beta cells. Sci. Signal. 2, ra23. doi: 10.1126/scisignal.2000278

Lemieux, B., Percival, M. D. and Falgueyret, J. P. (2004). Quantitation of the lysosomotropic character of cationic amphiphilic drugs using the fluorescent basic amine Red
DND-99. Anal. Biochem. 327, 247-251. doi: 10.1016/j.ab.2004 . 01.010

Li, J., Hou, N., Faried, A., Tsutsumi, S., and Kuwano, H. (2010). Inhibition of autophagy augments 5-fluorouracil chemotherapy in human colon cancer in vitro and in vivo model. Eur. J. Cancer 46, 1900-1909. doi: 10.1016/j.ejca.2010.02.02

Liang, C., Feng, P., Ku, B., Oh, B. H., and Jung, J. U. (2007a). UVRAG: a new player in autophagy and tumor cell growth. Autophagy 3, 69-71.

Liang, J., Shao, S. H., Xu, Z. X., Hennessy, B., Ding, Z., Larrea, M., et al. (2007b). The energy sensing LKB1-AMPK pathway regulates p27(kip1) phosphorylation mediating the decision to enter autophagy or apoptosis. Nat. Cell Biol. 9, 218-224. doi: 10.1038/ncb1537

Liang, X. H., Jackson, S., Seaman, M., Brown, K., Kempkes, B., Hibshoosh, H., et al. (1999). Induction of autophagy and inhibition of tumorigenesis by beclin 1. Nature 402, 672-676. doi: 10.1038/45257

Mallilankaraman, K., Cardenas, C., Doonan, P. J., Chandramoorthy, H. C., Irrinki, K. M., Golenar, T., et al. (2012). MCUR1 is an essential component of mitochondrial $\mathrm{Ca} 2+$ uptake that regulates cellular metabolism. Nat. Cell Biol. 14 1336-1343. doi: 10.1038/ncb2622

Mantovani, A., Allavena, P., Sica, A., and Balkwill, F. (2008). Cancerrelated inflammation. Nature 454 436-444. doi: 10.1038/nature07205

Marino, G., Salvador-Montoliu, N., Fueyo, A., Knecht, E., Mizushima, N., and LopezOtin, C. (2007). Tissue-specific autophagy alterations and increased tumorigenesis in mice deficient in Atg4C/autophagin-3. J. Biol. Chem. 282, 18573-18583. doi: 10.1074/jbc.M701194200

Mizushima, N. (2010). The role of the Atg1/ULK1 complex in autophagy regulation. Curr. Opin. Cell Biol. 22, 132-139. doi: 10.1016/j.ceb.2009.12.004

Mizushima, N., Levine, B., Cuervo, A. M., and Klionsky, D. J. (2008). Autophagy fights disease through cellular self-digestion. Nature 451, 1069-1075. doi: 10.1038 /nature06639

Monet, M., Lehen'kyi, V., Gackiere, F., Firlej, V., Vandenberghe, M., Roudbaraki, M., et al. (2010). Role of cationic channel TRPV2 in promoting prostate cancer migration and progression to androgen resistance. 
Cancer Res. 70, 1225-1235. doi: 10.1158/0008-5472.CAN-09-2205

Monteith, G. R., Davis, F. M., and Roberts-Thomson, S. J. (2012). Calcium channels and pumps in cancer: changes and consequences. J. Biol. Chem. 287, 31666-31673. doi: 10.1074/jbc.R112.343061

Monteith, G. R., McAndrew, D., Faddy, H. M., and Roberts-Thomson, S. J. (2007). Calcium and cancer: targeting $\mathrm{Ca} 2+$ transport. Nat. Rev. Cancer 7, 519-530. doi: $10.1038 / \mathrm{nrc} 2171$

Mori, A., Lehmann, S., O’kelly, J., Kumagai, T., Desmond, J. C., Pervan, M., et al. (2006). Capsaicin, a component of red peppers, inhibits the growth of androgen-independent, p53 mutant prostate cancer cells. Cancer Res. 66, 3222-3229. doi: 10.1158/0008-5472.CAN-05-0087

Muraki, K., Iwata, Y., Katanosaka, Y., Ito, T., Ohya, S., Shigekawa, M., et al. (2003). TRPV2 is a component of osmotically sensitive cation channels in murine aortic myocytes. Circ. Res. 93, 829-838. doi: 10.1161/01. RES.0000097263.10220.0C

Nguyen, H. T., Lapaquette, P., Bringer, M. A., and Darfeuille-Michaud, A. (2013). Autophagy and Crohn's Disease. J. Innate Immun. 5, 434-443. doi: 10.1159/000345129

Nilius, B. (2007). TRP channels in disease. Biochim. Biophys. Acta 1772, 805-812. doi: 10.1016/j.bbadis.2007.02.002

Nilius, B., Owsianik, G., Voets, T., and Peters, J. A. (2007). Transient receptor potential cation channels in disease. Physiol. Rev. 87, 165-217. doi: 10.1152/physrev.00021.2006

Parys, J. B., Decuypere, J. P., and Bultynck, G. (2012). Role of the inositol 14 , 5-trisphosphate receptor/Ca2+release channel in autophagy. Cell Commun. Signal. 10, 17. doi: 10.1186/1478-811X-10-17

Pattingre, S., Tassa, A., Qu, X., Garuti, R., Liang, X. H., Mizushima, N., et al. (2005). Bcl-2 antiapoptotic proteins inhibit Beclin 1-dependent autophagy. Cell 122, 927-939. doi: 10.1016/j.cell.2005. 07.002

Pedersen, S. F., Owsianik, G., and Nilius, B. (2005). TRP channels: an overview. Cell Calcium 38, 233-252. doi: 10.1016/j.ceca.2005.06.028

Peppiatt, C. M., Collins, T. J., Mackenzie, L., Conway, S. J., Holmes, A. B., Bootman, M. D., et al. (2003). 2Aminoethoxydiphenyl borate (2-APB) antagonises inositol 14 , 5-trisphosphate-induced calcium release, inhibits calcium pumps and has a use-dependent and slowly reversible action on storeoperated calcium entry channels. Cell Calcium 34, 97-108. doi: 10.1016/S0143-4160(03)00026-5

Pereira, G. J., Hirata, H., Fimia, G. M., Do Carmo, L. G., Bincoletto, C., Han, S. W., et al. (2011). Nicotinic acid adenine dinucleotide phosphate (NAADP) regulates autophagy in cultured astrocytes. J. Biol. Chem. 286, 27875-27881. doi: 10.1074/jbc.C110.216580

Prevarskaya, N., Skryma, R., and Shuba, Y. (2010). Ion channels and the hallmarks of cancer. Trends Mol. Med. 16, 107-121. doi: 10.1016/j.molmed.2010.01.005

Prevarskaya, N., Skryma, R., and Shuba, Y. (2011). Calcium in tumour metastasis: new roles for known actors. Nat. Rev. Cancer 11, 609-618. doi: 10.1038/nrc3105

Qiu, J., Tan, Y. W., Hagenston, A. M., Martel, M. A., Kneisel, N., Skehel, P. A., et al. (2013). Mitochondrial calcium uniporter $\mathrm{Mcu}$ controls excitotoxicity and is transcriptionally repressed by neuroprotective nuclear calcium signals. Nat. Commun. 4, 2034. doi: $10.1038 /$ ncomms 3034

Raimondi, S., Lowenfels, A. B., Morselli-Labate, A. M., Maisonneuve, P., and Pezzilli, R. (2010). Pancreatic cancer in chronic pancreatitis; aetiology, incidence, and early detection. Best. Pract. Res. Clin. Gastroenterol. 24, 349-358. doi: 10.1016/j.bpg.2010.02.007

Ravikumar, B., Sarkar, S., Davies, J. E., Futter, M., Garcia-Arencibia, M., Green-Thompson, Z. W., et al. (2010). Regulation of mammalian autophagy in physiology and pathophysiology. Physiol. Rev. 90, 1383-1435. doi: 10.1152/physrev.00030.2009

Razi, M., Chan, E. Y., and Tooze, S. A. (2009). Early endosomes and endosomal coatomer are required for autophagy. J. Cell Biol. 185, 305-321. doi: $10.1083 /$ jcb. 200810098

Riedel, K. G., Zwaan, J., Kenyon, K. R., Kolodny, E. H., Hanninen, L., and Albert, D. M. (1985). Ocular abnormalities in mucolipidosis IV. Am. J. Ophthalmol. 99, 125-136.

Rizzuto, R., De Stefani, D., Raffaello, A., and Mammucari, C. (2012). Mitochondria as sensors and regulators of calcium signalling. Nat. Rev. Mol. Cell Biol. 13, 566-578. doi: 10.1038/nrm3412

Rubinsztein, D. C., Codogno, P., and Levine, B. (2012). Autophagy modulation as a potential therapeutic target for diverse diseases. Nat. Rev. Drug Discov. 11, 709-730. doi: 10.1038/nrd3802

Saito, M., Hanson, P. I., and Schlesinger, P. (2007). Luminal chloride-dependent activation of endosome calcium channels: patch clamp study of enlarged endosomes. J. Biol. Chem. 282, 27327-27333. doi: 10.1074/jbc.M702557200

Sakaki, K., Wu, J., and Kaufman, R. J. (2008). Protein kinase Ctheta is required for autophagy in response to stress in the endoplasmic reticulum. J. Biol. Chem. 283, 15370-15380. doi: 10.1074/jbc.M710209200

Sarkar, S., Floto, R. A., Berger, Z., Imarisio, S., Cordenier, A., Pasco, M., et al. (2005). Lithium induces autophagy by inhibiting inositol monophosphatase. J. Cell Biol. 170, 1101-1111. doi: 10.1083/jcb.200504035

Selvakumaran, M., Amaravadi, R. K., Vasilevskaya, I. A., and O'dwyer, P. J. (2013). Autophagy inhibition sensitizes colon cancer cells to antiangiogenic and cytotoxic therapy. Clin. Cancer Res. 19, 2995-3007. doi: 10.1158/1078-0432.CCR-12-1542

Shapovalov, G., Lehen'kyi, V., Skryma, R., and Prevarskaya, N. (2011). TRP channels in cell survival and cell death in normal and transformed cells. Cell Calcium 50, 295-302. doi: 10.1016/j.ceca.2011.05.006

Slaugenhaupt, S. A., Acierno, J. S. Jr., Helbling, L. A., Bove, C., Goldin, E., Bach, G., et al. (1999). Mapping of the mucolipidosis type IV gene to chromosome $19 \mathrm{p}$ and definition of founder haplotypes. Am. J. Hum. Genet. 65, 773-778. doi: $10.1086 / 302549$

Son, S. M., Jung, E. S., Shin, H. J., Byun, J., and Mook-Jung, I. (2012). Abeta-induced formation of autophagosomes is mediated by RAGE-CaMKKbeta-AMPK signaling. Neurobiol. Aging 33, 1006 e1011-1006 e1023. doi: 10.1016/j. neurobiolaging.2011.09.039

Soyombo, A. A., Tjon-Kon-Sang, S., Rbaibi, Y., Bashllari, E., Bisceglia, J., Muallem, S., et al. (2006). TRP-ML1 regulates lysosomal $\mathrm{pH}$ and acidic lysosomal lipid hydrolytic activity. J. Biol. Chem. 281, 7294-7301. doi: 10.1074/jbc.M508211200

Sumoza-Toledo, A., and Penner, R. (2011). TRPM2: a multifunctional ion channel for calcium signalling. J. Physiol. 589, 1515-1525. doi: 10.1113/jphysiol.2010.201855

Takahashi, Y., Coppola, D., Matsushita, N., Cualing, H. D., Sun, M., Sato, Y., et al. (2007). Bif-1 interacts with
Beclin 1 through UVRAG and regulates autophagy and tumorigenesis. Nat. Cell Biol. 9, 1142-1151. doi: $10.1038 /$ ncb1634

Takamura, A., Komatsu, M., Hara, T., Sakamoto, A., Kishi, C., Waguri, S., et al. (2011). Autophagy-deficient mice develop multiple liver tumors. Genes Dev. 25, 795-800. doi: 10.1101/gad.2016211

Tanida, I., Ueno, T., and Kominami, E. (2004). LC3 conjugation system in mammalian autophagy. Int. J. Biochem. Cell Biol. 36, 2503-2518. doi: 10.1016/j.biocel. 2004.05.009

Thebault, S., Lemonnier, L., Bidaux, G., Flourakis, M., Bavencoffe, A., Gordienko, D., et al. (2005). Novel role of cold/menthol-sensitive transient receptor potential melastatine family member 8 (TRPM8) in the activation of store-operated channels in $\mathrm{LNCaP}$ human prostate cancer epithelial cells. J. Biol. Chem. 280, 39423-39435. doi 10.1074/jbc.M503544200

Toro, C. A., Arias, L. A., and Brauchi, S. (2011). Sub-cellular distribution and translocation of TRP channels. Curr. Pharm. Biotechnol. 12, 12-23.

Tsavaler, L., Shapero, M. H., Morkowski, S., and Laus, R. (2001). Trp-p8, a novel prostate-specific gene, is up-regulated in prostate cancer and other malignancies and shares high homology with transient receptor potential calcium channel proteins. Cancer Res. 61, 3760-3769.

Turner, H., Fleig, A., Stokes, A., Kinet, J. P., and Penner, R. (2003). Discrimination of intracellular calcium store subcompartments using TRPV1 (transient receptor potential channel, vanilloid subfamily member 1) release channel activity. Biochem. J. 371, 341-350. doi: 10.1042/BJ20021381

Venkatachalam, K., Wong, C. O. and Montell, C. (2013). Feast or famine: role of TRPML in preventing cellular amino acid starvation. Autophagy 9, 98-100. doi: 10.4161/auto. 22260

Venugopal, B., Mesires, N. T., Kennedy, J. C., Curcio-Morelli, C., Laplante, J. M., Dice, J. F., et al. (2009). Chaperone-mediated autophagy is defective in mucolipidosis type IV. J. Cell. Physiol. 219, 344-353. doi: 10.1002/jcp. 21676

Vergarajauregui, S., Connelly, P. S., Daniels, M. P., and Puertollano, R. (2008). Autophagic dysfunction in mucolipidosis type IV patients. Hum. Mol. Genet. 17, 2723-2737. doi: $10.1093 / \mathrm{hmg} / \mathrm{ddn} 174$ 
Vicencio, J. M., Ortiz, C., Criollo, A., Jones, A. W., Kepp, O., Galluzzi, L., et al. (2009). The inositol 1 4, 5-trisphosphate receptor regulates autophagy through its interaction with Beclin 1. Cell Death Differ. 16, 1006-1017. doi: 10.1038/cdd.2009.34

Wang, S. H., Shih, Y. L., Ko, W. C., Wei, Y. H., and Shih, C. M. (2008). Cadmium-induced autophagy and apoptosis are mediated by a calcium signaling pathway. Cell. Mol. Life Sci. 65, 3640-3652. doi: 10.1007/s00018-008-8383-9

White, E. (2012). Deconvoluting the context-dependent role for autophagy in cancer. Nat. Rev. Cancer 12, 401-410. doi: 10.1038/nrc3262

White, E., Karp, C., Strohecker, A. M., Guo, Y., and Mathew, R. (2010). Role of autophagy in suppression of inflammation and cancer. Curr. Opin. Cell Biol. 22, 212-217. doi: 10.1016/j.ceb.2009.12.008

Williams, A., Sarkar, S., Cuddon, P., Ttofi, E. K., Saiki, S., Siddiqi, F. H., et al. (2008). Novel targets for Huntington's disease in an mTORindependent autophagy pathway. Nat. Chem. Biol. 4, 295-305. doi: 10.1038/nchembio.79

Wong, C. O., Li, R., Montell, C., and Venkatachalam, K. (2012a). Drosophila TRPML is required for TORC1 activation. Curr. Biol. 22, 1616-1621. doi: 10.1016/j.cub.2012.06.055
Wong, R., Steenbergen, C., and Murphy, E. (2012b). Mitochondrial permeability transition pore and calcium handling. Methods Mol. Biol. 810, 235-242. doi: 10.1007/978-1-61779-382-0_15

Yang, S., Wang, X., Contino, G., Liesa, M., Sahin, E., Ying, H., et al. (2011a). Pancreatic cancers require autophagy for tumor growth. Genes Dev. 25, 717-729. doi: 10.1101/gad.2016111

Yang, Z. J., Chee, C. E., Huang, S., and Sinicrope, F. A. (2011b). The role of autophagy in cancer: therapeutic implications. Mol. Cancer Ther. 10, 1533-1541. doi: 10.1158/15357163.MCT-11-0047

Yousefi, S., Perozzo, R., Schmid, I., Ziemiecki, A., Schaffner, T., Scapozza, L., et al. (2006). Calpainmediated cleavage of Atg5 switches autophagy to apoptosis. Nat. Cell Biol. 8, 1124-1132. doi: 10.1038/ncb1482

Yue, Z., Jin, S., Yang, C., Levine, A. J., and Heintz, N. (2003). Beclin 1 , an autophagy gene essential for early embryonic development, is a haploinsufficient tumor suppressor. Proc. Natl. Acad. Sci. U.S.A. 100, 15077-15082. doi: 10.1073/pnas.2436255100

Zalckvar, E., Berissi, H., Eisenstein, M., and Kimchi, A. (2009a). Phosphorylation of Beclin 1 by DAP-kinase promotes autophagy by weakening its interactions with Bcl-2 and Bcl-XL. Autophagy 5,
720-722. doi: 10.4161/auto.5. 5.8625

Zalckvar, E., Berissi, H., Mizrachy, L., Idelchuk, Y., Koren, I., Eisenstein, M., et al. (2009b). DAP-kinasemediated phosphorylation on the $\mathrm{BH} 3$ domain of beclin 1 promotes dissociation of beclin 1 from Bcl-XL and induction of autophagy. EMBO Rep. 10, 285-292. doi: 10.1038/embor. 2008.246

Zeevi, D. A., Frumkin, A., OffenGlasner, V., Kogot-Levin, A., and Bach, G. (2009). A potentially dynamic lysosomal role for the endogenous TRPML proteins. J. Pathol. 219, 153-162. doi: 10.1002/path.2587

Zeevi, D. A., Lev, S., Frumkin, A., Minke, B., and Bach, G. (2010). Heteromultimeric TRPML channel assemblies play a crucial role in the regulation of cell viability models and starvationinduced autophagy. J. Cell Sci. 123, 3112-3124. doi: $10.1242 /$ jcs. 067330

Zhang, L., and Barritt, G. J. (2004) Evidence that TRPM8 is an androgen-dependent $\mathrm{Ca} 2+$ channel required for the survival of prostate cancer cells. Cancer Res. 64, 8365-8373. doi: 10.1158/0008-5472.CAN-04-2146

Zhang, X., Mak, S., Li, L., Parra, A., Denlinger, B., Belmonte, C., et al. (2012). Direct inhibition of the cold-activated TRPM8 ion channel by Galphaq. Nat. Cell Biol. 14, 851-858. doi: 10.1038/ ncb2529

Conflict of Interest Statement: The authors declare that the research was conducted in the absence of any commercial or financial relationships that could be construed as a potential conflict of interest.

Received: 15 June 2013; paper pending published: 24 July 2013; accepted: 11 September 2013; published online: 02 October 2013.

Citation: Kondratskyi A, Yassine $M$, Kondratska K, Skryma R, Slomianny $C$ and Prevarskaya N (2013) Calciumpermeable ion channels in control of autophagy and cancer. Front. Physiol. 4:272. doi: 10.3389/fphys.2013.00272

This article was submitted to Membrane Physiology and Membrane Biophysics, a section of the journal Frontiers in Physiology.

Copyright (๑) 2013 Kondratskyi, Yassine, Kondratska, Skryma, Slomianny and Prevarskaya. This is an open-access article distributed under the terms of the Creative Commons Attribution License (CC BY). The use, distribution or reproduction in other forums is permitted, provided the original author(s) or licensor are credited and that the original publication in this journal is cited, in accordance with accepted academic practice. No use, distribution or reproduction is permitted which does not comply with these terms. 